\title{
Effect of Botanical Extracts on Amino Acid and Fatty Acid Profile of Broiler Meat
}

-Author(s)
Waheed S'
Hasnain A'
Ahmad A'
Tarar OM"
Yaqeen Z"
Ali TM'
' Department of Food Science and
Technology, University of Karachi, Pakistan
" Pakistan Council of Scientific and Industrial

Research (PCSIR), Karachi, Pakistan

\section{Mail Address}

Corresponding author e-mail address Shahid Waheed

Department of Food Science and Technology, University of Karachi, Pakistan.

Email: shahid.waheed1976@gmail.com

\begin{abstract}
The objectives of current study were to evaluate the effect of botanical extracts as antioxidants on amino - and fatty acids profile of broiler meat. In total, 200 one-day-old broiler chicks were divided according to a completely randomized design into eight dietary treatments with five replicates of five chicks each. Dietary treatments were: $A$ - positive control (PC) with antibiotics and synthetic antioxidants, $B$ - negative control (NC), C - NC+Trigonellafoenum-graecum, D -NC+Nigella sativa seed, E-NC+Violaodorata, F-NC+Trachyspermumammi, G -PC+Trachy spermumammi+Trigonellafoenum-graecum+Violaodorata, and $\mathrm{H}-\mathrm{NC}+$ Trachyspermumammi, Trigonellafoenum-graecum and Viola odorata. Meat amino - and fatty acid contents were analyzed after slaughter at 35 days of age. Data were submitted to one-way analysis of variance and means were compared by Duncan's Multiple Range test. The levels of histidine, isoleucine, leucine, lysine and threonine were significantly higher $(p \leq 0.05)$ in the $H, F, E, H$ and $F$ groups respectively. Arginine, tryptophan, valine, methionine, and phenylalanine were significantly higher $(p \leq 0.05)$ in the $C, F, E, G$ and $H$ groups. Total essential amino acid levels were highest $(40.36 \%)$ in $\mathrm{C}$ group $(p \leq 0.05)$. The meat of $\mathrm{H}$ broilers presented significantly higher $(p \leq 0.05)$ unsaturated fatty acids $(54.8 \%)$ and omega-3 contents $(2.77 \%)$ and the lowest saturated fatty acid content (44.8\%). Group F present the highest linoleic acid and omega- 6 levels and group $H$ the highest $(p \leq 0.05)$ arachidonic and eicosapentaenoic acid (EPA) contents. It was concluded that botanical extracts aid health-beneficial meat production and the simultaneous inclusion of Trachyspermumammi, Trigonellafoenum-graecum, and Viola odorata in broiler diets is a more suitable option than the other dietary regimes.
\end{abstract}

\section{INTRODUCTION}

The poultry industry plays a vital role in supply of healthy meat products to the public. Broiler meat production from broiler is one of the major food-producing enterprises globally. Although broiler exhibits relatively fast growth rate and heavy body size, the nutritional profile of its meat has been criticized under conventional human dietary regimes (Fanatico et al., 2007).

The breast and thigh are the preferred parts of consumers of various regions. However, the chemical composition of meat fat, including its amino acid and fatty acids profile, have been currently intensively researched due to their direct association with cardiovascular diseases in humans. The accretion of amino acids like lysine in skeletal satellite cells in the muscle is largely influenced by the activation of insulinlike growth factor (IGF-1) (Tesseraud et al., 2003).Plant extracts, like that of Aloe vera, can enhance muscle integrity by elevating IGF-1 
Waheed S, Hasnain A, Ahmad A, Tarar OM, Yaqeen Z, Ali TM
Effect of Botanical Extracts on Amino Acid and Fatty Acid Profile of Broiler Meat
(Muhammad et al., 2013). It was demonstrated that curcumin extracts enhance the growth performance of pigs by regulating the gene expression of /GF-1 and up regulating the activity of antioxidant enzymes (Upadhaya et al., 2016). Muscular health and growth are well regulated by curcumin feeding (Alamdari et al., 2009). Botanical extracts can aid muscle regeneration and differentiation, reduce muscle atrophy and enhance anti-inflammatory responses (Rondanelli et al., 2016).

Fatty acid composition of dietary fats can affect saturated fatty acids (SFA) as well as unsaturated fatty acids (UFA) levels in broiler breast and thigh muscles (Zhang et al., 2013). Fat sources rich in UFA can be included in broiler diets to produce leaner meat with much better $\omega$-3 profiles. The desired $\omega$-3 fatty acids, such as linolenic acid (LNA), eicosapentaenoic acid (EPA), docosapentaenoic acid (DPA) and docosahexaenoic acid (DHA), in the breast and thighs of chicks can be achieved by using omega 3 rich oils (Sadeghi et al., 2012). Unfortunately, UFA-rich oils are subjected to faster oxidative stress and the inclusion of rancid fats with high peroxide value can impair broiler performance and severely affect immunity (McGill et al., 2011).

The dietary addition of antioxidants can improve broiler performance and immunity by reducing thiobarbituric acid levels in liver and increasing serum and liver vitamin A and E concentrations (Taverez et al., 2011). The supplementation of broiler feeds with plant-derived rich in antioxidant compounds enhance oxygen scavenging responses to safeguard fat sources, both outside and inside body. This effect of natural antioxidants reflects results in a decline in cholesterol and triglyceride levels (Ahmed et al., 2015). Phenolic compounds like quercetin and vitamin $\mathrm{E}$ decrease fatty acid generation, particularly of SFA (Sohaib et al., 2015). Antioxidant-rich diets potentially inhibit saturated fatty acid levels is by modulating the activity of 9-desaturase enzyme complex, which converts SFA into UFA (Gnoni et al., 2009). A researcher group documented a declining trend in SFA production in the breast muscle of broilers fed gallic acid and linoleic acid (Jung et al., 2010). Similarly, the inclusion genistein and hesperidin in broiler diets reduced SFA level in the breast meat (Kamboh \& Zhu, 2013). Black cumin seeds can be used up to $1.5 \%$ in layer feed to reduce egg cholesterol and enhance UFA content in egg yolk (Yalc et al., 2009). Chia seed in diet also effective in controlling fat content in meat and significantly lowering SFA content eventually having better SFA: UFA and $\omega-6: \omega-3$ ratio in muscles (Ayerza et al., 2002). Feeding layers with black cumin seeds decreased yolk triglyceride content and cholesterol level in up to $40 \%$ (Nabiela et al., 2006).

Recent studies have shown that nutrition has a major influence on tissue gene expression. Dietary antioxidant supplements from plant sources can enhance the quality of meat by minimizing oxidative stress on lipids and protein molecules and enhancing the activities of glutathione peroxidase, catalase, and superoxide dismutase, ultimately improving the amino acid and fatty acid profile of meat (Upton et al., 2009). Due to their potential health benefits, consumers are willing to buy meat from broilers fed botanical extracts (Rizzo et al., 2008). After reviewing the potentials of natural extracts, this study aimed at evaluating the effects of the dietary inclusion of botanical extracts on the amino acid and fatty acid profiles of broiler meat.

\section{MATERIALS AND METHODS}

\section{Preparation of Trachyspermumammi, Trigonellafoenum-graecum, Nigella sativa and Viola odorata extracts}

Dried flowers of Viola odorata (sweet violet) and seeds of Trigonellafoenum-graecum (fenugreek), Nigella sativa (black cumin) and Trachyspermumammi (Ajwain) were purchased from local sources. Seeds were ground to $30-\mathrm{mm}$ particle size. The processes of sonication and extraction were performed according to the methodology proposed by Kim \& Lee (2002). Briefly, $200 \mathrm{~g}$ of each sample were soaked in 2-L flask with $1 \mathrm{~L}$ of $80 \%$ methanol. After the sonication for 24 hours, samples were filtered, and again submitted to sonication for 24 hours. Filtrates were transferred to round bottom flasks on a rotary evaporator at $40^{\circ} \mathrm{C}$ and allowed to evaporate until the $300 \mathrm{~mL}$ of the contents remained, which then were standardized to $400 \mathrm{~mL}$ by adding distilled water.

\section{Experimental design and bird management}

Birds were reared at Research and Development Farm of Sindh Feed, Pvt. Limited, Pakistan. The laboratory analysis of the meat and eggs were performed at the Department of Food Science \& Technology, University of Karachi and Pakistan Council for Scientific \& Industrial Research (PCSIR) Laboratories Complex, Karachi, Pakistan.

A total of 200 one-d-oldRoss-308 broilers were divided into eight treatments with five replicates of five birds each according to a completely randomized design. Bird were reared on litter at a stocking density 
$0.6 \mathrm{ft}^{2} / \mathrm{bird}$ for a period of 35 days. A photoperiod of 22 hours of light and 2 hours of darkness was applied.

Isocaloric (23, 21.12 and $20 \%$ crude protein) and isonitrogenous (3000, 3300 and $3200 \mathrm{kcal} / \mathrm{kg}$ ) diets (starter, grower and finisher respectively) were formulated according to recommendations of the Ross308 manual using ingredients available in the market. The software FeedLive was used for diet formulation (Table 1).

Table 1 - Ingredients and nutritional composition of the starter, grower, and finisher broiler diets (Ross 308 standards)

\begin{tabular}{|c|c|c|c|c|c|c|c|}
\hline Ingredients & Starter & Grower & Finisher & Nutrient composition & Starter & Grower & Finisher \\
\hline Yellow corn (90\% DM) & 58.15 & 61.8 & 59.7 & Metabolizable energy (kcal/kg) & 3000 & 3300 & 3200 \\
\hline Soybean meal Argentina & 31.25 & 28.25 & 21.25 & Crude protein \% & 23 & 21.12 & 20.0 \\
\hline Fish meal $50 \%$ C.P & 4.25 & 2.75 & 2.0 & Calcium \% & 0.92 & 0.87 & 0.81 \\
\hline Canola meal & 0 & 0 & 6.2 & Available phosphorus \% & 0.48 & 0.44 & 0.42 \\
\hline Sunflower meal 33\% C.P & 2.0 & 1.75 & 3.2 & & & & \\
\hline Limestone/ Marble & 1.0 & 1.075 & 0.93 & Digestible lysine \% & 1.28 & 1.153 & 1.03 \\
\hline Sodium bicarbonate. & 0.2 & 0.225 & 0.2 & Digestible Met+Cys \% & 0.95 & 0.872 & 0.8 \\
\hline Salt ( $\mathrm{NaCl})$ & 0.175 & 0.20 & 0.2 & Digestible arginine \% & 1.37 & 1.234 & 1.136 \\
\hline Choline chloride $70 \%$ & 0.2 & 0.20 & 0.2 & Digestible Tryptophan \% & 0.238 & 0.214 & 0.195 \\
\hline Sunflower oil & 1.5 & 2.5 & 5 & Digestible Threonine \% & 0.858 & 0.775 & 0.711 \\
\hline Lysine sulphate & 0.33 & 0.33 & 0.28 & Digestible isoleucine \% & 0.86 & 0.787 & 0.708 \\
\hline D. L methionine & 0.3 & 0.28 & 0.23 & Digestible valine \% & 0.96 & 0.872 & 0.813 \\
\hline L-Threonine & 0.135 & 0.12 & 0.1 & Linoleic acid \% & 2.1 & 2.7 & 4.061 \\
\hline L- Isoleucine & 0 & 0.01 & 0 & Sodium \% & 0.20 & 0.20 & 0.19 \\
\hline *Phyzyme 10000 TPT & 0.010 & 0.010 & 0.01 & Chloride \% & 0.22 & 0.21 & 0.20 \\
\hline ** Vitamin/ mineral premix & 0.50 & 0.50 & 0.5 & Potassium & 0.99 & 0.99 & 0.92 \\
\hline TOTAL & 100 & 100 & 100 & & & & \\
\hline
\end{tabular}

*Phyzyme 10000 TPT contained phytase 10000 FTU/g

** Vitamin and mineral premix provided per kilogram of diet: vitamin A, $12.000 \mathrm{lU}$; cholecalciferol, $3.000 \mathrm{IU}$; vitamin E, $80 \mathrm{mg}$; vitamin K3, $3.2 \mathrm{mg}$; vitamin B1, $3.2 \mathrm{mg}$; vitamin B2, 8.6 mg; niacin 65 mg; vitamin B6, 4.3 mg; vitamin B12, 20 нg; Ca-D- pantothenate, 20 mg; Folic acid, 2 mg; biotin, 0.2 mg; Mn, 120 mg; Zn, 110 mg; Fe, 60 mg; Cu, 16 mg; Se, 0.3 $\mathrm{mg}$, lodine $1.25 \mathrm{mg}$

Treatment groups were:

A: Positive control (PC) diet containing an antibiotic (lincomycin $(4.4 \%)$ at $100 \mathrm{mg} / \mathrm{kg}$ ); vitamin $\mathrm{E}$ at $40 \mathrm{mg} / \mathrm{kg}$ and a commercial synthetic antioxidant product at $150 \mathrm{mg} / \mathrm{kg}$ (SELDOX ${ }^{\circledR}$, Trow Nutrition, Netherlands), contain ingethoxyquin, BHA, BHT and citric acid.

B: Negative control (NC), diet with no inclusion of antioxidants or antibiotics.

$\mathrm{C}: \mathrm{NC}+$ supplemented with fenugreek crude extract at $1 \mathrm{ml} / \mathrm{kg}$ diet.

D: NC + supplemented with black cumin seed crude extract $1 \mathrm{~mL} / \mathrm{kg}$ diet

$\mathrm{E}: \mathrm{NC}+$ supplemented with sweet violet crude extract $1 \mathrm{~mL} / \mathrm{kg}$ diet.

F: NC + supplemented with ajwain extracts $1 \mathrm{~mL}$ $\mathrm{kg}$ feed

G: PC + supplemented with ajwain, fenugreek and sweet violet extracts, each at $0.5 \mathrm{~mL} / \mathrm{kg}$ feed.

$\mathrm{H}$ : NC + supplemented with ajwain, fenugreek and sweet violet extracts, each at $0.5 \mathrm{~mL} / \mathrm{kg}$ feed.

\section{Parameters evaluated}

At 35 days of age, birds were slaughtered, and eviscerated. Carcass yield (\%) was calculated by the following equation.

$$
\text { Carcass } \%=\frac{\text { Carcass weight }}{\text { Live weight }} \times 100
$$

Breast and thighs were cut up from the carcass using sharp knives and their yields (\%)were calculated on whole carcass basis using following equations.

$$
\begin{aligned}
& \text { Breast } \%=\frac{\text { Breast weight }}{\text { Carcass weight }} \times 100 \\
& \text { Thigh } \%=\frac{\text { Thigh weight }}{\text { Carcass weight }} \times 100
\end{aligned}
$$

\section{Amino Acid Analysis}

Breast and thigh meat samples were collected to determine their amino acid profile. Briefly, 50-mg samples were hydrolyzed for $18 \mathrm{~h}$ in $6 \mathrm{~N} \mathrm{HCl}$. The sample container was sealed to prevent oxidation and stored at $110^{\circ} \mathrm{C}$ for hydrolysis. The amino acid composition of 
the meat samples all birds fed the A, B, C, D, E, F, G and $\mathrm{H}$ diets was determined according to the method of Schuster (1988) using an amino acid analyzer. Samples were extracted in citrate buffer $(2.2 \mathrm{pH})$ solution followed by filtration to obtain a clear solution of the free amino acids. An aliquot of this clear filtrate was injected into the column (Shim-pack ISC-07/S1504 Na) of the HPLC-based amino acid analyzer (RF-10AXL, Shimadzu Corporation, Tokyo, Japan) equipped with fluorescence detector (FLD-6A). Sodium hypochlorite and o-phthalaldehyde solutions were used as reaction solutions for post-column derivation of amino acids.

\section{Fatty Acid Analysis}

For fatty acid analysis, fats were hydrolyzed and fatty acids were derived from total fat content according to the procedure of O'Fallon et al. (2007). Briefly, $50 \mu \mathrm{L}$ of fat/oil was placed in a Pyrex screw cap tube, and $1 \mathrm{~mL}$ of internal standard, $0.7 \mathrm{~mL} \mathrm{KOH}$ solution and almost $5.3 \mathrm{~mL}$ of methanol were added and mixed. Tubes were capped and placed on a preheated water bath at $55^{\circ} \mathrm{C}$ for 90 minutes. The tubes were then cooled in water followed by $\mathrm{H}_{2} \mathrm{SO}_{4}$ addition in the samples. The tubes were then again kept in water bath at $55^{\circ} \mathrm{C}$ for 1.5 hours, followed by cooling and addition of $3 \mathrm{~mL}$ of hexane. Tubes were then placed into a vortex mixer for 5 minutes. The fatty acid methyl ester (FAME) hexane layer (upper layer) was separated, filtered and then analyzed. Gas chromatography was performed in GC-2010 apparatus (Shimadzu Corp., Japan) 07947 equipped with FID detector, split injector and SP-2560 silica fused capillary column (100m $\times 0.25 \mathrm{~mm} \times 0.2 \mu \mathrm{m}$, Supelco) under the following operating program: injection volume $1 \mu \mathrm{L}$ at $250^{\circ} \mathrm{C}$, detector temperature of $260^{\circ} \mathrm{C}$, column temperature of $140^{\circ} \mathrm{C}$ for 5 minutes and then ramped to $240^{\circ} \mathrm{C}$ at $4^{\circ} \mathrm{C}$ per minute, remained stable for 15 minutes. Helium was used as carrier gas at flow rate of $1.12 \mathrm{~mL}$ min and linear velocity of $20 \mathrm{~cm} / \mathrm{s}$; split ratio 1:100.
Results were expressed as percentages relative to FID response area.

\section{Statistical Analysis}

The collected data were subjected to one-way analysis of variance (Steel et al., 1997)using the SPSS Statistics 20.0 software (IBM Deutschland $\mathrm{GmbH}$, Ehningen, Germany) and means were compared using Duncan's Multiple Range (DMR) test (Duncan, 1955) following the statistical model:

$$
\begin{aligned}
& Y_{i j}=\mu+T_{i}+\varepsilon_{i j} \\
& \text { Where, } \\
& Y_{i j}=\text { Observation of dependent variable recorded on } \\
& i^{\text {th }} \text { treatment } \\
& \mu=\text { Population mean } \\
& \mathrm{T}_{\mathrm{i}}=\text { Effect of } \mathrm{i}^{\text {th }} \text { treatment ( } \mathrm{i}=8 \text { i.eA, B, C, D, E, F, } \\
& \mathrm{G} \text { and } \mathrm{H} \text { ) } \\
& \varepsilon_{i j}=\text { Residual effect of } j^{\text {th }} \text { observation on } i^{\text {th }} \text { treatment } \\
& \mathrm{NID} \sim 0, \sigma^{2}
\end{aligned}
$$

\section{RESULTS AND DISCUSSION}

\section{Carcass traits}

Average carcass yield parameters are shown in Table 2. Thigh yields were significantly different $(p \leq 0.05)$ among the dietary treatments. Maximum thigh yield $(20.6 \pm 0.115)$ was determined in the birds fed the positive control diet. The lower carcass yield of the birds fed botanical extracts may be due to the fat content in their carcasses, as fat contribute to total carcass weight (Table 2). Tavarez et al. (2011) also

\begin{tabular}{|c|c|c|c|c|}
\hline Treatments & Carcass & Thigh & Breast & Fats \\
\hline A (Positive control; PC) & $66.5 \pm 0.173^{d}$ & $20.6 \pm 0.115^{c}$ & $21.0 \pm 0.115^{d}$ & $7.20 \pm 0.056^{d}$ \\
\hline B (Negative control; NC) & $64.5 \pm 0.173^{a b}$ & $18.0 \pm 0.577^{a}$ & $19.0 \pm 0.577^{a}$ & $7.53 \pm 0.066^{e}$ \\
\hline $\mathrm{C}(\mathrm{NC}+$ fenugreek $)$ & $64.1 \pm 0.0^{a}$ & $19.6 \pm 0.23^{b c}$ & $20.2 \pm 0.115^{b c}$ & $6.60 \pm 0.00^{\mathrm{bc}}$ \\
\hline $\mathrm{D}(\mathrm{NC}+$ black cumin seed $)$ & $64.4 \pm 0.23^{\mathrm{ab}}$ & $18 \pm 0.773^{a}$ & $18.87 \pm 0.881^{a}$ & $6.50 \pm 0.115^{b c}$ \\
\hline $\mathrm{E}(\mathrm{NC}+$ sweet violet $)$ & $64.0 \pm 0.115^{a}$ & $18 \pm 0.577 a$ & $18.8 \pm 0.057^{a}$ & $5.00 \pm 0.115^{\mathrm{a}}$ \\
\hline $\mathrm{F}(\mathrm{NC}+$ ajwain $)$ & $64.8 \pm 0.23^{b}$ & $17.8 \pm 0.115^{b}$ & $19.87 \pm 0.666^{b}$ & $6.73 \pm 0.666^{c}$ \\
\hline$G(P C+$ ajwain+ fenugreek+sweet violet) & $65.4 \pm 0.115^{c}$ & $19.0 \pm 0.058^{a b}$ & $23.6 \pm 0.346^{e}$ & $6.40 \pm 0.057^{b}$ \\
\hline $\mathrm{H}$ (NC+ajwain+fenugreek+sweet violet) & $64.0 \pm 0.208^{a}$ & $19.8 \pm 0.115^{b c}$ & $20.73 \pm 0.105^{c d}$ & $6.43 \pm 0.12^{b}$ \\
\hline$p$-value & 0.000 & 0.000 & 0.000 & 0.000 \\
\hline
\end{tabular}
observed that feeding antioxidant to broilers had no effect on carcass weight, carcass or breast meat yield, but in general increased serum vitamin $\mathrm{E}$ and vitamin A levels. The highest breast meat yield was obtained in group $G$, which was fed the positive control diet supplemented with antioxidants from botanical sources. Botanically-derived compounds like curcumin

Table $\mathbf{2}$ - Carcass yield of broilers fed botanical extracts

Means \pm SE within a column with different lowercase letters are significantly different at $(p \leq 0.05)$ 
have been used to promote muscle health, strength and growth (Nkukwana et al., 2014). Similarly, scientific reviews on the effects of botanical extracts on muscle health (Rondanelli et al., 2016) describe their positive role in muscle growth and integrity.

\section{Essential amino acid profile of broiler meat}

The meat contents of essential amino acids, including histidine, isoleucine, leucine, lysine and threonine were significantly $(p \leq 0.05)$ lower in the negative control group (diet B) compared to all other treatments (Table 3). The breast meat of group $\mathrm{H}$ birds presented the highest $(p \leq 0.05)$ histidine $(4 \%)$ levels (Table 3). Isoleucine level (4.5\%) was significantly $(p \leq 0.05)$ in the meat of birds fed ajwain extracts (diet F) and leucine $(7 \% ; p \leq 0.05)$ in the meat of those fed sweet violet extract (diet E). The highest lysine level $(9.1 \%)$ was achieved with diet $\mathrm{F}$ and the lowest with the negative-control diet (B) (Table 3). Threonine $(4.2 \%)$ levels were higher better $(p \leq 0.05)$ in the meat of broilers fed ajwain extracts. The breast meat of birds fed fenugreek extract (diet C) presented higher arginine (5.9\%; $p \leq 0.05)$ compared with the other treatments (Table 3 ). Meat tryptophan values (Table 3) were significantly higher $(p \leq 0.05)$ in the F-group broilers $(1.2 \%)$ and valine $(4.1 \% ; p \leq 0.05)$ in E-group broilers compared with all other treatments. Table 3 shows higher meat methionine content in group $G$ and phenylalanine in group $H$, both significantly higher $(p \leq 0.05)$ than in the other groups. The meat of broilers fed sweet violet extract (diets contained the low esttryptophan, methionine and phenylalanine levels (Table 3). The breast meat of group $C$ broilers presented the highest sum of all essential amino acids (40.36\%) followed by group $\mathrm{H}$ (40.19), both of which were significantly higher $(p \leq 0.05)$ than other groups. The essential amino acid analysis of the broilers fed negative control diet showed that it contained lower values of many essential amino acids compared with those fed the other tested diets. The feeding of botanical extracts to broilers in general increased the individual levels of essential amino acids, and consequently the sum of all essential amino acid.

The overall improvement of essential amino acid contents in the meat of broilers fed the plant extracts suggest the potential benefits of their inclusion in broiler diets. These results may be due to the presence of bioactive compounds in the evaluated herbs. The findings of the current study are supported by reports of the presence of sulfur and non-sulfur compounds in Allium sativum (Amagase et al., 2001). Some of

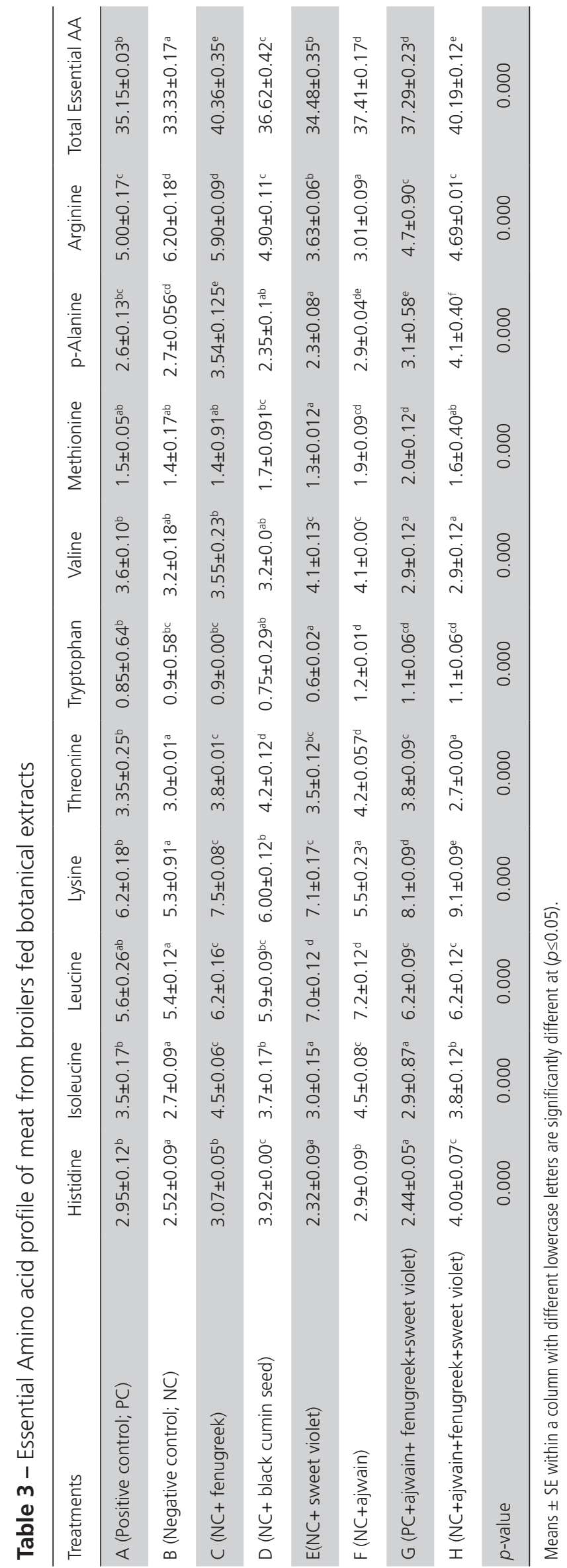


these compounds are reported as alliin (Puvača et al., 2015) composed of the sulfur-containing amino acid $\gamma$-L-glutamyl-S-allyl-L-cysteines and S-allyl-Lcysteine sulfoxides (Stoll \& Seebeck, 1948), methiin, (+)-S-(trans-1-propenyl)-L-cysteine sulfoxide, and cycloalliin (Fujiwara et al., 1958).

\section{Non-essential amino acid profile of broiler meat}

There was a significant $(p \leq 0.05)$ increase in nonessential amino acid levels (46\%) in the breast meat of birds fed sweet violet extract (diet E), as shown in Table 4.The meat of broilers fed the $\mathrm{E}$ diet meat presented higher proline $(4.5 \%)$, glycine $(6.8 \%)$ and alanine $(8.2 \%)$ contents compared with the other treatments $(p \leq 0.05)$. The meat from birds fed ajwain extract had significantly $(p \leq 0.05)$ higher tyrosine $(3.6 \%)$, cysteine $(1.4 \%)$ and total amino acid values $(80.81 \%)$ than that of the other treatments (Table 4). Diet D promoted significantly higher $(p \leq 0.05)$ aspartic acid values $(14.5 \%)$ as compared with the other diets (Table 4$)$. The lowest values $(p \leq 0.05)$ of tyrosine, aspartic acid and, consequently, of total non-essential amino acids were obtained in the meat of broiler fed the $G$ diet (Table 5).

Higher non-essential amino acids levels were obtained in the meat of broilers feds weet violet extract, and the combination of fenugreek, ajwain and sweet violet extracts resulted in a decline in meat non-essential amino acid content. Total amino acids contents were better in all groups supplemented with antioxidants from plant-derived sources. The process of muscle growth and protein accretion in broilers was best described by Tesseraud et al. (2003), who explained that the accretion of amino acids like lysine in skeletal muscle satellite cells is greatly influenced by the activation of insulin-like growth factor (IGF-1). Antioxidant-rich botanical extracts from plants like Aloe vera boost the biological role of IGF-1 to modulate energy kinetics, myoglobin accretion and muscular integrity (Muhammad et al., 2013). Muscle health and growth may be regulated by feeding curcumin, which was shown to improve broiler growth performance by regulating IGF-1 gene expression and enhancing the activity of antioxidant enzymes (Upadhaya et al., 2016; Alamdari et al., 2009). Recently, Rondanelli et al.,(2016) described that botanical extracts may aid muscle regeneration and differentiation, reduce muscle atrophy, and demonstrated it has antiinflammatory and anti-fatigue properties, preventing muscle damage. 
Table 5 - Fatty acid profile (C15-C22) of meat from broilers fed botanical extracts

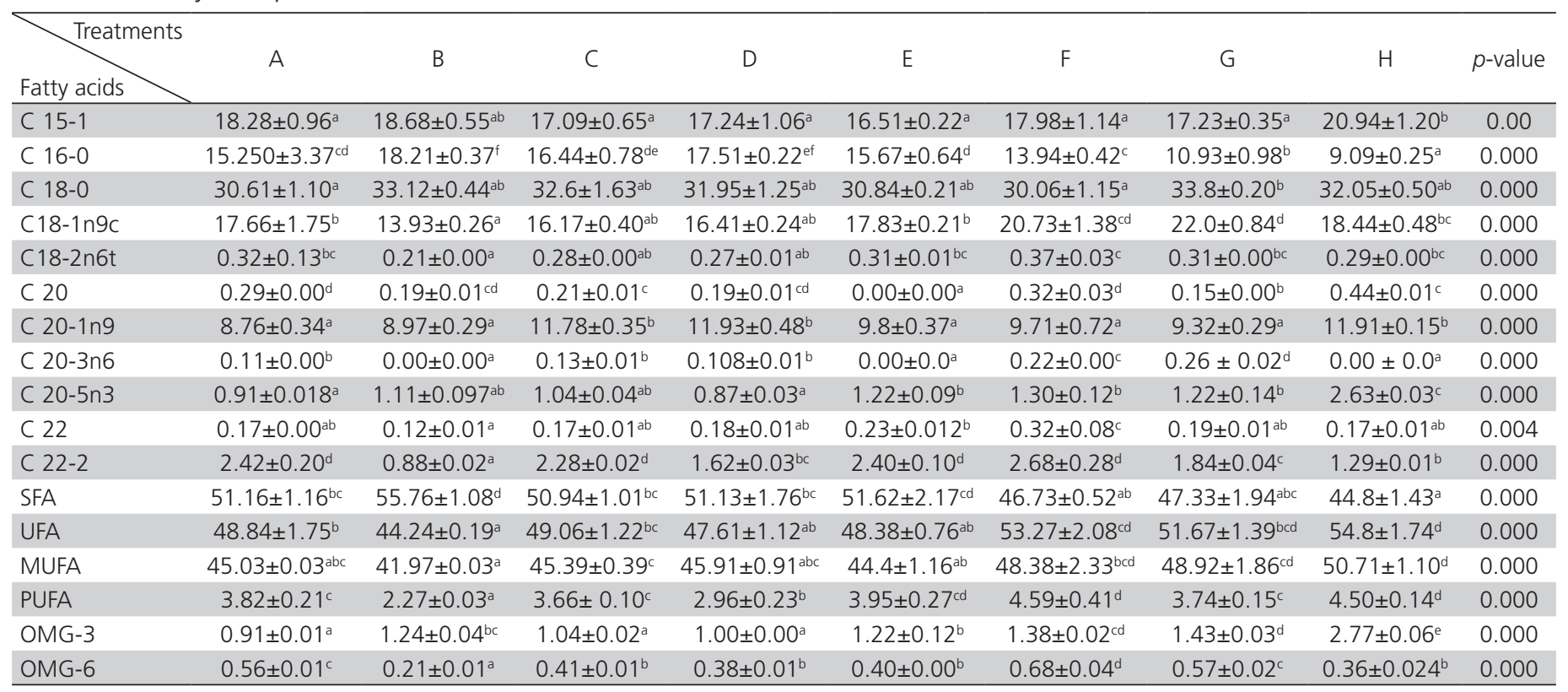

Means \pm SE within a row with different lowercase letters are significantly different at $(p \leq 0.05)$.

C 15-1 = pentadecanoic acid; C 16-0 = palmitic acid; C 18-0 = stearic acid; C18-1n9c = oleic acid; C18-2n6t = linoleic acid; C 20= arachidonic acid; C 20-1n9 = eicosenoic acid; C 20-3n6 = eicosatrienoic acid; C 20-5n3 = eicosapentaenoic acid; C 22 = behenic acid; C 22-2 = docosadienoic acid; SFA = saturated fatty acids; UFA = unsaturated fatty acids; MUFA = monounsaturated fatty acids; PUFA = polyunsaturated fatty acids; OMG-3 = omega-3 fatty acids; 0MG $-6=$ omega- 6 fatty acids.

\section{Meat Fatty Acid Composition}

The results of the meat fatty acid analysis are shown in Table 5. Pentadecanoic acid (C15-1) levels of $18.68 \%$ and $20.94 \%$ were determined in the $\mathrm{B}$ and $\mathrm{H}$ groups, respectively, and both were significantly $(p \leq 0.05)$ higher than all other groups. Palmitic acid (C16) level was highest (18.21\%) in the broilers fed the negativecontrol diet (group B) and lowest in those group $\mathrm{H}$ $(9.09 \%)$, both at $p \leq 0.05$. The highest $(p \leq 0.05)$ stearic acid values were obtained in group $\mathrm{H}(33.8 \%)$ and the lowest $(p \leq 0.05)$ in Groups A (30.61\%) and F (30.06\%). Oleic acid levels were significantly $(p \leq 0.05)$ higher in group G (22\%) and lower in group B (13.93\%), respectively, than in the other groups. Linoleic acid $(C 18-2 n 6)$ values obtained were significantly $(p \leq 0.05)$ higher in group $\mathrm{F}$ and lower in group B $(0.21 \%)$ than in the other groups. Arachidonic acid (C20) was significantly higher $(p \leq 0.05)$ in group $\mathrm{H}$ chicken fats $(0.44 \%)$ compared with other groups. Eicosenoic acid (C20-1n9) values in groups $C(11.78 \%)$ and $D$ $(11.93 \%)$ were higher $(p \leq 0.05)$ compared with the other groups. The meat of broilers in group $\mathrm{G}$ presented higher eicosatrienoic acid (C20-3n6) levels compared with the other treatments $(p \leq 0.05)$. The highest eicosapentaenoic acid (EPA: C20-5n) was determined in group $H(2.63 \% ; p \leq 0.05)$. The highest $(p \leq 0.05)$ behenic (C22) and docosadienoic (C22-2) acids levels were obtained in broilers fed ajwain extracts. The meat of the broilers fed the negative control diet presented the highest saturated fatty acid (SFA; 55.76\%) levels $(p \leq 0.05)$, and the lowest unsaturated fatty acid (UFA; $41.47 \%$ ) and polyunsaturated fatty acid (PUFA; $2.24 \%$ ) levels compared with other groups. Group $H$ presented had significantly higher $(p \leq 0.05)$ UFA $(54.8 \%)$ and mono-unsaturated fatty acid (MUFA; $50.71 \%$ ) levels compared with other all groups (Table 5). Maximum PUFA was observed in group $F$ samples (4.59\%) followed by group $\mathrm{H}(4.5 \%)$ and both were significantly better than other groups. Higher omega-3 fatty acid levels were obtained in groups $F, G$ and $H$. Group $\mathrm{H}$ presented the highest omega-3 fatty acid level $(2.77 \%)$ compared with the other groups $(p \leq 0.05)$, which was almost three-fold higher than that obtained with the positive control diet $(0.91 \%)$. The meat of broilers in groups C, D, E, F and G presented $1.04 \%$, $1.0 \%, 1.22 \%, 1.38 \%$, and $1.43 \%$ omega-3 levels, respectively, which were significantly higher than obtained with the positive control diet $(p \leq 0.05)$. The highest and the lowest omega- 6 levels were obtained in groups $\mathrm{F}(0.68 \%)$ and $\mathrm{B}(0.21 \%)$, respectively, both were significantly different from the other groups $(p \leq 0.05)$.

The inclusion of botanical extracts in broiler diets in the present study resulted in a remarkable increase in the meat levels of unsaturated fatty acids and a clear decline in saturated fats. The meat of the broilers 
Waheed S, Hasnain A, Ahmad A, Tarar OM, Yaqeen Z, Ali TM
Effect of Botanical Extracts on Amino Acid and Fatty Acid Profile of Broiler Meat fed the negative-control diet (B group) presented the highest SFA and lowest UFA levels among all groups. On the other hand, the meat of broilers fed the negative control diet with the combination of the evaluated botanical extract (group $\mathrm{H}$ ) contained 10\% more UFA due to the reduction of almost $10 \%$ SFA, almost the double of PUFA and three times higher omega-3 and omega- 6 fatty acids compared with the B group (negative control). It was demonstrated that UFA levels and UFA/SFA ratios in the breast and drumstick meat increased with the dietary supplementation of 2 or $5 \%$ olive oil (Zhang et al., 2013). The inclusion of black cumin seeds in layer diets resulted in better fatty acid profiles and lower cholesterol and triglyceride levels in the egg (Yalc et al., 2009; Nabiela et al., 2006). Similarly, the botanical compound quercetin reduced SFA levels in broiler fats, especially of myristic and stearic acids (Sohaib et al., 2015). Basil seed and chamomile in broiler diet reduced muscle lipid and triglyceride levels (Ahmed et al., 2015). It was demonstrated that chia seeds reduced SFA and SFA:PUFA and omega6:omega-3 ratios in chicken meat (Ayerza et al., 2002). The meat fatty acid profiles obtained in the present study when botanical extracts were included in the diet are consistent with the results of Nkukwana et al. (2014), who reported higher C18,C 18-3n6,C 20, C20-2,C 20-3n6 and C 15 contents in the breast meat of broilers fed Moringa olifera leaf meal. It is very clear that botanical extracts with high levels of antioxidant compounds can protect oils and proteins in living tissues (Zhang et al., 2010).

\section{CONCLUSION}

The extracts of spices and sweet violet flowers evaluated positively influenced broiler physiology. Overall, they improved meat quality as shown by the higher meat content of amino acids (especially of essential AA), as well as by the reduced meat levels of saturated fatty acids and the increased levels of UFA, MUFA, PUFA, and omega-3 and optimal fatty acid ratios. In conclusion, the evaluated natural botanical antioxidants are good modulators of amino acid and fatty acid contents in broiler meat, and the inclusion of a combination of ajwain, fenugreek and sweet violet extracts in the diet may efficiently replace the conventional antibiotic growth promoters.

\section{ACKNOWLEDGMENTS}

The authors would like to thank PCSIR Laboratories Complex, Karachi, Pakistan for providing us opportunity to conduct research work in their laboratories and to conduct the experimental trial in animal research station.

\section{CONFLICT OF INTEREST STATEMENT}

We declare that we have no conflict of interest

\section{REFERENCES}

Ahmed A, Kadry M, Sadek, Ayman E. Impact of two herbal seeds supplementation on growth performance and some biochemical blood and tissue parameters of broiler chickens. Life Sciences Research 2015;3:112-127.

Amagase H., Petesch BL, Matsuura H, Kasuga S, Itakura Y. Intake of garlic and its bioactive components. Journal of Nutrition 2001;131:955S-962S.

Alamdari N, O'Neal P, Hasselgren PO. Curcumin and muscle wasting-a new role for an old drug? Nutrition 2009;25:125-129.

Ayerza R, CoateW, Lauria M. Chia seed (Salvia hispanica I.) as an $\omega$-3 fatty acid source for broilers:influence on fatty acid composition, cholesterol and fat content of white and dark meats, growth performance, and sensory characteristics. Poultry Science 2002;81:826-837.

Duncan DB. Multiple range and multiple F tests. Biometrics 1955;11:1-42.

Fanatico AC, Pillai PB, Emmert JL, Owens CM. Meat quality of slow- and fast-growing chicken genotypes fed low nutrient or standard diets and raised indoors or with outdoor access. Poultry Science 2007;86:22452255.

Fujiwara M., Yishimura M, Tsuno S, Murakami F. 'Allithiamine,' a newly found derivative of vitamin B1. IV. on the alliin homologues in the vegetables. The Journal of Biochemistry 1958;45:141-149.

Gnoni G, Paglialonga G, Siculella L. Quercetin inhibits fatty acid and triacylglycerol synthesis in rat liver cells. European Journal of Clinical Investigations 2009;39:761-768.

Jung S, Choe JH, Kim B, Yun H, Kruk, ZA, Jo C. Effect of dietary mixture of gallic acid and linoleic acid on antioxidative potential and quality of breast meat from broilers. Meat Science 2010;2:520-526.

Kamboh AA, Zhu WY. Effect of increasing levels of bioflavonoids in broiler feed on plasma anti-oxidative potential, lipid metabolites, and fatty acid composition of meat. Poultry Science 2013;92 (2):454-461.

Kim DO, Lee CY. Extraction and isolation of polyphenolics. In: Wrolstad RE. Current protocols in food analytical chemistry. New York : John Wiley 2002. p.1081-1092.

McGill J, McGill E, Kamyab A. Firman JD. Effect of high peroxide value fats on performance of broilers in a normal immune state. International Journal of Poultry Science 2011;2:241-246.

Muhammad LRH, Dwi GAL, Hendra S, Adeodatus YH. Effect of aloe vera extract to the insulin-like growth factor-1 (IGF-1) levels from visceral fat tissue in Rattus Norvegicus Wistar diabetes mellitus. Proceeding of International Conference on Biological Sciences; 2013 Sep 20-21; Yogyakarta. Indonésia. p.174-179.

Nabiela M, Bagir E, Aziza Y, Rania H, Hamed M, Ahmed G, et al. Lipid composition of egg yolk and serum in laying hens fed diets containing black cumin (Nigella sativa). International Journal of Poultry Science 2006;5:574-578.

Nkukwana T, Muchenje V, Masika P, Hoffman L, Dzama K, Descalzo A. Fatty acid composition and oxidative stability of breast meat from broiler chickens supplemented with Moringa oleifera leaf meal over a period of refrigeration. Food Chemistry 2014;142:255-261. 
Waheed S, Hasnain A, Ahmad A, Tarar OM, Yaqeen Z, Ali TM Acid Profile of Broiler Meat
O'Fallon JV, Busboom JR, Nelson ML, Gaskins CT. A direct method for fatty acid methyl ester synthesis:Application to wet meat tissues, oils and feed stuff. Journal of Animal Science 2007;85:1511-1521.

Puvača N, Ljubojević D, Kostadinović LJ, Luckac D, Lević J, Popović S, et al. Spices and herbs in broilers nutrition:Effects of garlic (Allium sativum L.) on broiler chicken production. World's Poultry Science Journal 2015:71:533-538.

Rizzo, PV, Menten, JFM, Racanicci, AMC, Santarosa, J. Foundation and perspectives of the use of plant extracts as performance enhancers in broilers. Revista Brasileira de Ciência Avícola 2008,10(4);195-204.

Rondanelli M, Miccono A, Peroni G. Guerriero F, Morazzoni P, Riva A, et al. Systematic review on the effects of botanicals on skeletal muscle health in order to prevent Sarcopenia. Evidence-Based Complementary and Alternative Medicine 2016. Available from: http://dx.doi. org/10.1155/2016/5970367.

Sadeghi AS, Iranvani, H, Torshizi MK, Chamani M. Fatty acids profiles in meat of broiler chicks fed diet containing corn oil switched to fish oil at different weeks of age. World Applied Sciences Journal 2012;18(2):159-165

Schuster R. Determination of amino acids in biological, pharmaceutical, plant and food samples by automated precolumn derivatization and high-performance liquid chromatography. Journal of Chromatography 1988;431:271-284.

Sohaib M, Butt MS, Shabbir MA, Shahid M. Lipid stability, antioxidant potential and fatty acid composition of broilers breast meat as influenced by quercetin in combination with $\alpha$-tocopherol enriched diets. Lipids in Health Diseases 2015;14:

SPSS - Statistical Package for the Social Sciences. SPSS for windows. Chicago: IBM Deutschland $\mathrm{GmbH} ; 2017$

Steel RGD, Torrie GH, Dickey DA. Principles and procedures of statistics, a biometrical approach. $3^{\text {rd }}$ ed. New York: MacGraw Hill; 1997.
Stoll A, Seebeck E. Allium compounds. I. Alliin the true mother compound of garlic oil. Helvetica Chimica Acta 1948;31:189-210.

Taverez MA, Boler DC, Bess KN, Zhao J, Yan F, Dilger AC, et al. Effect of antioxidant inclusion and oil quality on broiler performance, meat quality, and lipid oxidation. Poultry Science. 2011;90(4):922-930.

Tesseraud S, Pym RAE, Bihon-Duval EL, Duclos MJ. Response of broilers selected on carcass quality to dietary protein supply: live performance, muscle development, and circulating insulin-like growth factor (IGF-I and -II). Poultry Science 2003;82:1011-1016.

Upadhaya SD, Park JW. Kim IH. Effect of plant extract YGF251 on growth performance, reproductive performance and insulin like growth factor secretion in primiparous and multiparous sows. Animal Nutrition and Feed Technology 2016;16:393-402.

Upton JR, Edens FW. The effects of dietary oxidized fat and selenium source on performance, glutathione peroxidase, and glutathione reductase activity in broiler chickens. Journal of Applied Poultry Research 2009;18:193-202

Yalc S, Yalc S, Erol H. Effects of dietary black cumin seed (Nigella sativa L.) on performance, egg traits, egg cholesterol content and egg yolk fatty acid composition in laying hens. Journal of the Science of Food and Agriculture 2009;89:1737-1742.

Zhang Y, Yang L, Zu Y, Chen X, Wang F, Liu F. Oxidative stability of sunflower oil supplemented with carnosic acid compared with synthetic antioxidants during accelerated storage. Food Chemistry 2010;118:656-662.

Zhang ZF, Zhou TX, Kim IH. Effect of dietary olive oil on growth performance, carcass parameters, serum characteristics and fatty acid composition of breast and drumstick meat in broilers. Asian Australasian Journal of Animal Science 2013;26(3):416-422 
